\section{References}

1. Dartevelle P, Macchiarini P. Sleeve pneumonectomy. In: Deslauriers J, Faber LP, editors. Pneumectomy, part I. Philadelphia: W.B. Saunders; Philadelphia, Chest Surg Clinic North Am 407-417, 1999.

2. Grillo HC. Tracheal replacement. J Thorac Cardiovasc Surg. 2003;125: 975-6.
3. Fuchs JR, Nasseri BA, Vacanti JP. Tissue engineering: a 21st century solution to surgical reconstruction. Ann Thorac Surg. 2001;72:577-91.

4. Mertsching H, Leyh R, Rebe P, et al. Tissue engineered autologous heart-valves-results after 3,6, and 9 month implantation in a sheep model. J Artif Organs. 2001;24:574-7.

5. Grillo HC. Tracheal replacement: a critical review. Ann Thorac Surg. 2002;73:1995-2003.

\title{
Two-conduit repair for anomalous origin of the left coronary artery from the pulmonary artery in an adult
}

Hassan Kattach, MD, MRCS, Kyriakos Anastasiadis, MD, Xu Yu Jin, PhD, and Ravi Pillai, FRCS, Oxford, United Kingdom

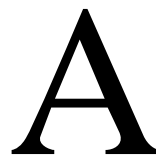

nomalous origin of the left coronary artery from the pulmonary artery (ALCAPA) presenting in adult life is rare. Although it is surgically treated in most cases, the preferred procedure offering the best short- and long-term outcomes is still unknown. We present the case of a patient who was successfully treated by a 2-conduit repair.

\section{Clinical Summary}

A 41-year-old previously healthy man presented with acute onset chest pain and left bundle branch block on his electrocardiogram. No increase of cardiac enzymes was detected. Echocardiogram showed a dilated and severely impaired left ventricle, but all valves were normal. Cardiac catheterization demonstrated a grossly dilated right coronary artery. The contrast material retrogradely filled a dilated left coronary system through the collateral vessels. The left coronary system in turn drained into the pulmonary artery (PA) (Fig 1). A contrast computed tomographic scan confirmed that the left coronary artery (LCA) was arising from the PA.

Surgical procedure. Anatomically it was not possible to translocate the LCA. Therefore, an intrapulmonary tunnel was constructed by first creating an aortopulmonary window; then, with a PA homograft patch as a baffle, the window was connected to the LCA ostium. In addition, the left internal thoracic artery (LITA)

\footnotetext{
From the Department of Cardiothoracic Surgery, John Radcliffe Hospital, Oxford, United Kingdom.

Received for publication Feb 24, 2004; accepted for publication March 26, 2004.

Address for reprints: Ravi Pillai, FRCS, Department of Cardiothoracic Surgery, John Radcliffe Hospital, Headley Way, Headington, Oxford OX3 9DU, United Kingdom (E-mail: ravi.pillai@nds.ox.ac.uk).

J Thorac Cardiovasc Surg 2004;128:641-2

$0022-5223 / \$ 30.00$

Copyright @ 2004 by The American Association for Thoracic Surgery doi:10.1016/j.jtcvs.2004.03.050
}

was grafted to the left anterior descending artery (LAD). The pa-

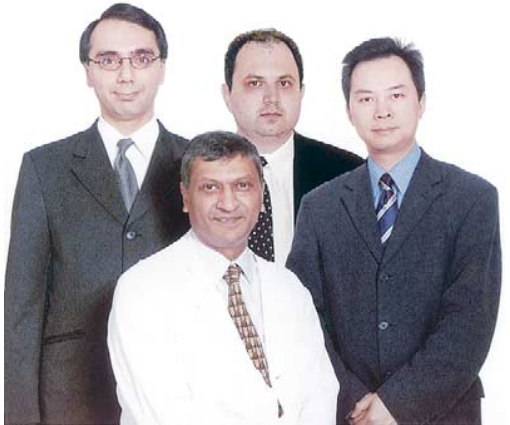

Drs Kattach, Anastasiadis, Jin, Pillai tient made an uneventful recovery.

Coronary angiography was performed 6 months postoperatively and showed a patent intrapulmonary tunnel supplying the circumflex system and a patent LITA graft to the LAD. It also revealed a reduction in size of the coronary arteries (Fig 2). Left ventricular function improved (ejection fraction increased from $30 \%$ preoperatively to $40 \%$ postoperatively, and left ventricular end-diastolic diameter was mildly decreased from 65 to $60 \mathrm{~mm}$ on echocardiogram). In addition, the stress myocardial perfusion study demonstrated good perfusion, with no evidence of scarring. Clinically, the patient reported continued improvement in exercise tolerance.

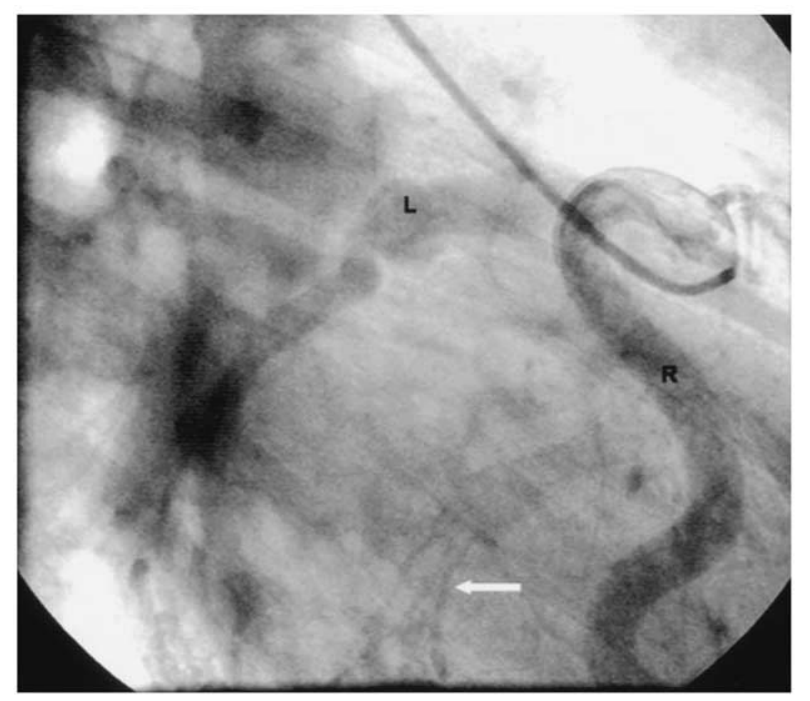

Figure 1. Right coronary artery angiogram. Dilated right coronary artery (R) fills the LCA system (L) by collateral vessels (arrow). 

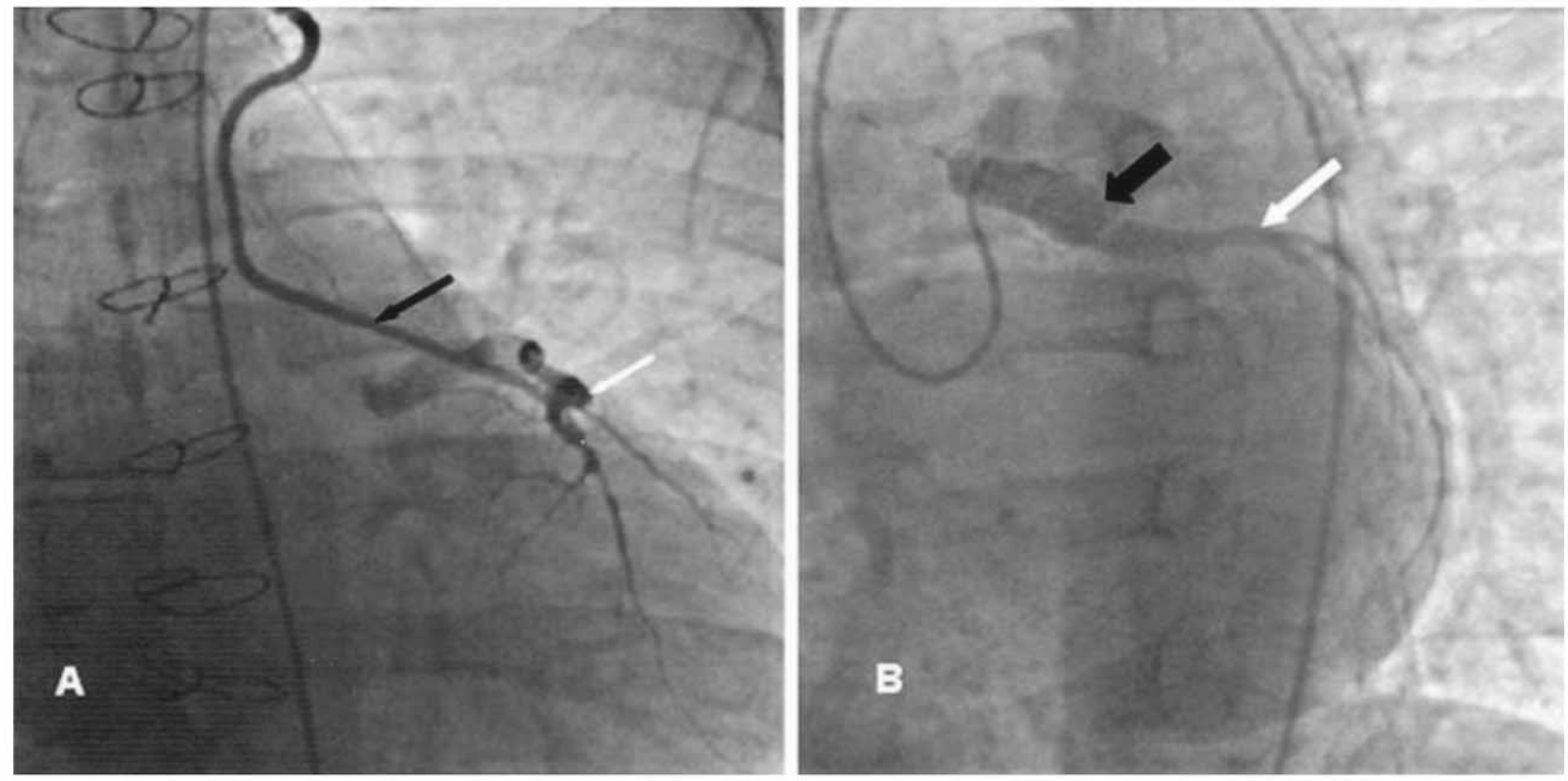

Figure 2. Postoperative angiogram. A, LITA (black arrow) supplying the LAD (white arrow). B, Contrast injection into the constructed tunnel (black arrow) supplying the circumflex (white arrow).

\section{Discussion}

ALCAPA is a rare anomaly, usually presenting in the neonatal period and requiring surgical correction. Several cases of ALCAPA presenting in adulthood have been reported. ${ }^{1}$

The surgical repair for adult patients aims to restore a normal circulation, preferably with native conduits. The optimum technique is direct reimplantation of the LCA to the ascending aorta. However, the coronary artery anatomy may not make this feasible, as in our case. Alternative procedures include bypass grafting, arterial or venous, of the ligated anomalous $\mathrm{LCA}^{2}$ or construction of an intrapulmonary tunnel. ${ }^{3,4}$

The PA homograft was used in our case instead of pericardium or synthetic material because the former carries a higher risk of aneurysm formation (because of the high pressure within the baffle) and the latter is more thrombogenic. The PA may need to be further enlarged with a patch. However, this was not necessary in our case, because the intrapulmonary tunnel did not occupy significant space to obstruct the PA. The LITA to LAD graft was used to ensure adequate left coronary circulation should the tunnel fail, because the left system contracted on restoration of antegrade flow. The preoperative diameter of the LAD was $10 \mathrm{~mm}$, and its response to normal flow restoration was unknown. The late postoperative angiogram demonstrated its usefulness and abolished any concerns regarding its occlusion because of competitive flow.

It has been suggested that ALCAPA presenting in adulthood can be treated conservatively ${ }^{5}$; however, surgical correction can achieve better outcome and symptomatic control.

\section{References}

1. Purut CM, Sabiston DC Jr. Origin of the left coronary artery from the pulmonary artery in older adults. $J$ Thorac Cardiovasc Surg. 1991;102:566-70.

2. Chan RK, Hare DL, Buxton BF. Anomalous left main coronary artery arising from the pulmonary artery in an adult: treatment by internal mammary artery grafting. J Thorac Cardiovasc Surg. 1995;109:393-4.

3. Takeuchi S, Imamura H, Katsumoto K, Hayashi I, Katohgi T, Yozu R, et al. New surgical method for repair of anomalous left coronary artery from pulmonary artery. J Thorac Cardiovasc Surg. 1979;78:7-11.

4. Alexi-Meskishvili V, Berger F, Weng Y, Lange PE, Hetzer R. Anomalous origin of the left coronary artery from the pulmonary artery in adults. J Card Surg. 1995;10(4 Pt 1):309-15.

5. Fierens C, Budts W, Denef B, Van De Werf F. A 72 year old woman with ALCAPA. Heart. 2000;83:E2. 